\title{
Uveitis with occult choroiditis due to Mycobacterium kansasii: limitations of interferon-gamma release assay (IGRA) tests (case report and mini-review on ocular non-tuberculous mycobacteria and IGRA cross-reactivity)
}

\author{
Tatiana I. Kuznetcova • Alain Sauty • \\ Carl P. Herbort
}

Received: 1 April 2012/ Accepted: 5 May 2012/Published online: 2 June 2012

(C) Springer Science+Business Media B.V. 2012

\begin{abstract}
Ocular tuberculosis is difficult to diagnose but should be suspected when uveitis fails to respond to inflammation suppressive therapy. Interferon-gamma release assays (IGRAs) represent a substantial help to diagnose suspected ocular tuberculosis especially in non-endemic areas. Indocyanine green angiography (ICGA) is able to detect clinically silent choroiditis that, when associated with a positive IGRA test, should lead the clinician to suspect ocular tuberculosis, warranting specific therapy. The fact that IGRA tests can also react with some atypical strains of mycobacteria is not always known. We report here a case with resistant post-operative inflammation that presented
\end{abstract}

T. I. Kuznetcova · C. P. Herbort $(\square)$

Retinal and Inflammatory Diseases, Centre for

Ophthalmic Specialised Care (COS), Rue de la Grotte 6,

1003 Lausanne, Switzerland

e-mail: carl.herb@bluewin.ch

T. I. Kuznetcova

e-mail: brionika@gmail.com

T. I. Kuznetcova

Department of Ophthalmology, I.P. Pavlov State Medical University, Saint-Petersburg, Russia

A. Sauty

Pulmonology and Immunology Consultations, Morges

Hospital, Morges, Switzerland

A. Sauty · C. P. Herbort

University of Lausanne, Lausanne, Switzerland with occult ICGA-detected choroiditis and a positive IGRA test that was most probably due to the nontuberculous mycobacterium (NTM) Mycobacterium kansasii. A 66 year-old man presented with a resistant cystoid macular oedema (CMO) in his left eye after combined cataract and epiretinal membrane surgery. At entry, his best-corrected visual acuity (BCVA) was 0.5 for far and near OS. Intraocular inflammation measured by laser flare photometry was elevated in the left eye $(54.4 \mathrm{ph} / \mathrm{ms})$ and also in the right eye (50.9 ph/ms). Four subTenon's injections of $40 \mathrm{mg}$ of triamcinolone did not produce any substantial improvement. Therefore a complete uveitis work-up was performed. Fluorescein angiography showed CMO OS and ICGA showed numerous hypofluorescent dots and fuzziness of choroidal vessels in both eyes. Among performed laboratory tests, the QuantiFERON $^{\circledR}$-TB Gold test was positive. After a pulmonological examination disclosing a right upper lobe infiltrate, the patient was started on a triple antituberculous therapy. Bronchial aspirate, obtained during bronchoscopy, was Ziehl-positive and culture grew M. kansasii. Nine months later, BCVA OS increased to 1.0 and flare decreased to $40.2 \mathrm{ph} / \mathrm{ms}$. The CMO OS resolved angiographically and did not recur with a macula still slightly thickened on OCT. Suspected ocular tuberculosis based on clinical findings and a positive IGRA test can, in rare instances, be due to atypical mycobacteria that also produce positive IGRA tests such as M. kansasii, M. szulgai, M. gordonae, M. flavescens and M. marinum. In our case failure to 
isolate the atypical mycobacterium would not have had negative therapeutic consequences, as $M$. kansasii is sensitive to the standard anti-tuberculous treatments, which is not the case with other NTMs.

Keywords Atypical mycobacteria $\cdot$ Mycobacterium kansasii · Choroiditis · Uveitis · Presumed ocular tuberculosis · IGRA tests · Indocyanine green angiography

\section{Introduction}

Ocular tuberculosis in non-endemic areas is usually more discreet and diagnosis is more difficult than in endemic areas. Moreover, unlike in endemic areas, polymerase chain reaction (PCR) identification of Mycobacterium tuberculosis DNA in ocular fluids is often negative. The choroid is frequently involved in ocular tuberculosis [1] but choroiditis can sometimes be very faint. The most sensitive method to explore and monitor the inflammatory involvement of the choroid is indocyanine green angiography (ICGA) often detecting subclinical choroidal inflammation [2]. For example, subclinical presumed tuberculous choroiditis was detected using ICGA in a patient presenting with isolated papillitis and responded to anti-tuberculous therapy alone [3]. ICGA was also the most useful method to follow interferon-gamma release assay (IGRA)-positive multifocal-serpiginous choroiditis [4].

Significant clinical evidence indicates that IGRAs are more specific than the purified protein derivative (PPD) skin tests in diagnosing tuberculosis as it is not confounded by prior bacillus Calmette-Guérin (BCG) vaccination and one of the two tests also being significantly more sensitive than the PPD skin test [5]. QuantiFERON $^{\circledR}$-TB Gold (Cellestis; Carnegie, Australia) is one of the IGRA tests using a whole-blood enzyme-linked immunosorbent assay, which measures the release of interferon gamma (IFN- $\gamma$ ) in response to three allegedly $M$. tuberculosis complex-specific proteins (M. tuberculosis, M. africanum, M. bovis). The detection and quantification of IFN- $\gamma$ released by $\mathrm{T}$ cells in response to ESAT-6, CFP-10 and TB7.7 (p4) proteins is the basis of this test. These proteins are absent from BCG strain and from most non-tuberculous mycobacteria (NTM) with the exception of M. kansasii, M. szulgai, M. marinum, M. gordonae,
M. flavescens, and M. gastri [6, 7]. Ingen et al. [8], however, were unable to demonstrate that genes encoding ESAT-6 and CFP-10 are present in $M$. flavescens, but revealed it in $M$. riyadhense. Consequently, a positive result of the IGRA test is a support for diagnosing tuberculous uveitis, but can also indicate diseases caused by a few other mycobacteria (Table 1). Therefore disease caused by some NTMs cannot be excluded by this test. Although NTMs are rare causative agents of ocular infections, NTMs produced sporadic cases of keratitis, scleritis, endophthalmitis, orbital granuloma and chorioretinitis [9-12]. M. riyadhense and M. gastri, however, have not yet been shown to cause ocular infections.

It is commonly accepted that the combination of a positive IGRA test and a compatible clinical picture indicates ocular tuberculosis until proven otherwise and specific therapy should be applied [3, 4, 13, 14].

We present a case with resistant post-surgical inflammation presenting cystoid macular oedema (CMO) in one eye as well as bilateral occult, ICGAdetected choroiditis associated with a positive IGRA test where culture was finally positive for $M$. kansasii and which responded to standard anti-tuberculous therapy.

\section{Case report}

A 66 year-old male patient had undergone surgery for a combined cataract and epiretinal membrane (ERM) in his left eye one year prior to being seen in our centre. Vision recovered to 1.0 after the operation; however, 4 months later vision decreased again to 0.6 OS and a CMO was seen on fluorescein angiography (FA) and optical coherence tomography (OCT; Heidelberg Engineering, Inc., Heidelberg, Germany). An intraocular injection of $4 \mathrm{mg}$ of triamcinolone was performed with an improvement of the OCT scans but a stagnation of visual acuity around 0.5 and an increase of intraocular pressure to $32 \mathrm{mmHg}$.

$\mathrm{He}$ was referred to the Centre for Ophthalmic Specialised care (COS), Lausanne, Switzerland, for a resistant post-operative CMO at the end of February 2011. At entry, his treatment for the left eye included Azopt $^{\circledR}$ BID, prednisolone acetate $1 \%$ drops BID, indomethacin $0.1 \%$ drops $6 \times$ daily and Diamox ${ }^{\circledR}$ $375 \mathrm{mg} /$ day. The best-corrected visual acuity was 1.25 for far and 1.0 for near OD and 0.5 for far and near OS. 
Table 1 Cross-reactivity in IGRA tests

\begin{tabular}{|c|c|c|c|c|c|c|c|}
\hline Tuberculosis complex & ESAT-6 & CFP-10 & TB7. $7^{\mathrm{a}}$ & Environmental strains & ESAT-6 & CFP-10 & $\mathrm{TB}^{2} 7^{\mathrm{a}}$ \\
\hline M. tuberculosis & + & + & + & M. abcessus & - & - & - \\
\hline M. africanum & + & + & + & M. avium & - & - & - \\
\hline M. bovis & + & + & + & M. gordonii & + & + & + \\
\hline BCG substrain & & & & M. kansasii & + & + & + \\
\hline Gothenburg & - & - & - & M. szulgai & + & + & + \\
\hline Moreau & - & - & - & M. marinum & + & + & + \\
\hline Tice & - & - & - & M. gastri & + & + & + \\
\hline Tokyo & - & - & - & M. flavescens & \pm & \pm & \pm \\
\hline Danish & - & - & - & M. riyadhense & \pm & \pm & \pm \\
\hline Glaxo & - & - & - & M. fortuitum & - & - & - \\
\hline Montreal & - & - & - & M. branderi & - & - & - \\
\hline \multirow[t]{10}{*}{ Pasteur } & - & - & - & M. intracellulare & - & - & - \\
\hline & & & & M. malmoense & - & - & - \\
\hline & & & & M. scrofulaceum & - & - & - \\
\hline & & & & M. smegmatis & - & - & - \\
\hline & & & & M. terrae & - & - & - \\
\hline & & & & M. vaccae & - & - & - \\
\hline & & & & M. xenopi & - & - & - \\
\hline & & & & M. oenavense & - & - & - \\
\hline & & & & M. celatum & - & - & - \\
\hline & & & & M. chelonae & - & - & - \\
\hline
\end{tabular}

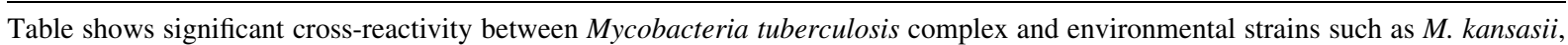
M. szulgai, M. marinum, M. gordonae, M. flavescens, M. gastri, M. flavescens and M. riyadhense (modified from Quest Diagnostics Incorporated and Biomerieux)

${ }^{\text {a }}$ QuantiFERON only

Intraocular pressures were 22 and $28 \mathrm{mmHg}$, respectively, for the left and right eyes. Intraocular inflammation measured by laser flare photometry (LFP) was elevated on the left with a value of $54.4 \mathrm{ph} / \mathrm{ms}$ (normal values, 3-6 ph/ms). Surprisingly, his right eye also had an elevated flare with a value of $50.9 \mathrm{ph} / \mathrm{ms}$. A CMO was seen in the left eye and confirmed by OCT (Fig. 1). Visual field testing using Octopus ${ }^{\circledR}$ (HaagStreit, Bern, Switzerland) showed no significant visual field impairment on either side and microperimetry displayed a mild diminished retinal sensitivity in the left eye with a test score of $364 / 560$ versus $460 / 560$ OD.

As the case was considered a resistant postoperative CMO no uveitis work-up was performed at initial presentation. Four subTenon's injections of $40 \mathrm{mg}$ of triamcinolone were performed on the left side at 3-4 week intervals. Four months later the situation had not changed substantially on the left with a BCVA of 0.6 , intraocular pressure of $14 \mathrm{mmHg}$, inflammation remaining at $52.1 \mathrm{ph} / \mathrm{ms}$ and a CMO quasi identical on OCT to the situation at entry (Fig. 1).

Therefore a complete uveitis work-up was performed with the following findings. FA showed $\mathrm{CMO}$ on the left and disc hyperfluorescence OU (Fig. 2).

ICGA indicated hypofluorescent dots and fuzziness of choroidal vessels in both eyes (Fig. 3). Among performed laboratory examinations, the QuantiFER$\mathrm{ON}^{\circledR}$-TB Gold test was positive suggesting sensitisation to the M. tuberculosis complex. When this result was given to the patient he recalled having been treated for tuberculosis as a youngster.

Prior to the initiation of a specific treatment, a chest $\mathrm{X}$-ray was performed since the patient had been treated a few months earlier by amoxicillin/clavulanic acid for a right upper lobe pneumonia with nocturnal sweats and a loss of $5 \mathrm{~kg}$. An infiltrate in the right 

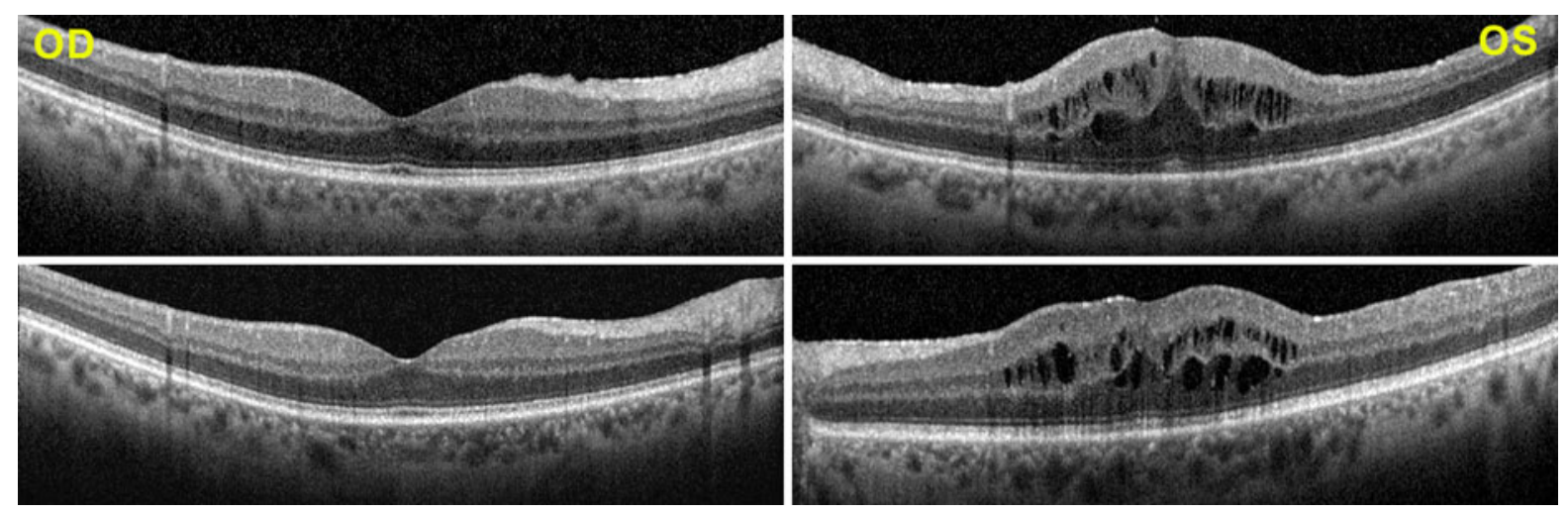

Fig. 1 OCTs of right and left maculas at presentation (top two pictures) and after four sub-Tenon's triamcinolone injections OS (two bottom pictures). Extensive cystoid macular oedema

seen OS at presentation (top right picture) and quasi identical cystoid macular oedema after four subTenon's triamcinolone injections (bottom right)

Fig. 2 FA showing cystoid macular oedema in the left eye (bottom pictures)
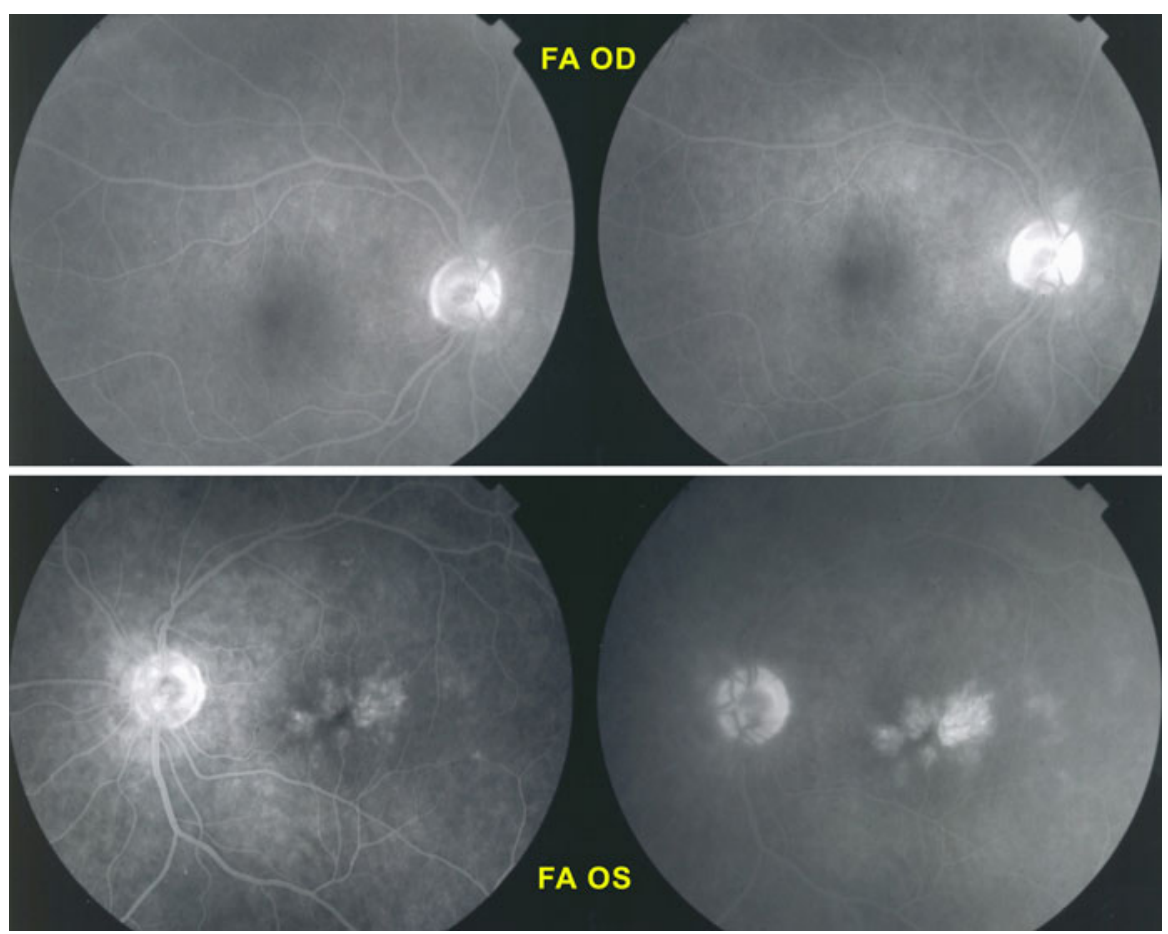

upper lobe was still present. Smears of bronchial aspirate obtained during a flexible bronchoscopy disclosed 1-10 acid-fast bacilli/field but PCR for $M$. tuberculosis was negative. The patient was then started on a triple anti-tuberculous therapy including isoniazid, rifampicin and ethambutol. Surprisingly, the bronchial aspirate culture came back positive for M. kansasii, which is susceptible to classical antituberculous treatment. The therapy was therefore continued.
Five months later, BCVA was $1.25 \mathrm{OD}$ and increased to 0.9 OS. Intraocular pressure was normal at $14 \mathrm{mmHg}$ OU. Inflammation measured by LFP still amounted to $35.1 \mathrm{ph} / \mathrm{ms}$ OD and had improved to $42.8 \mathrm{ph} / \mathrm{ms}$ OS. The CMO improved markedly on OCT for the first time (Fig. 4).

FA was within normal limits on both sides and there were neither hypofluorescent spots nor fuzziness of choroidal vessels seen on ICGA any more. At no time during nine months of follow-up did the CMO recur 

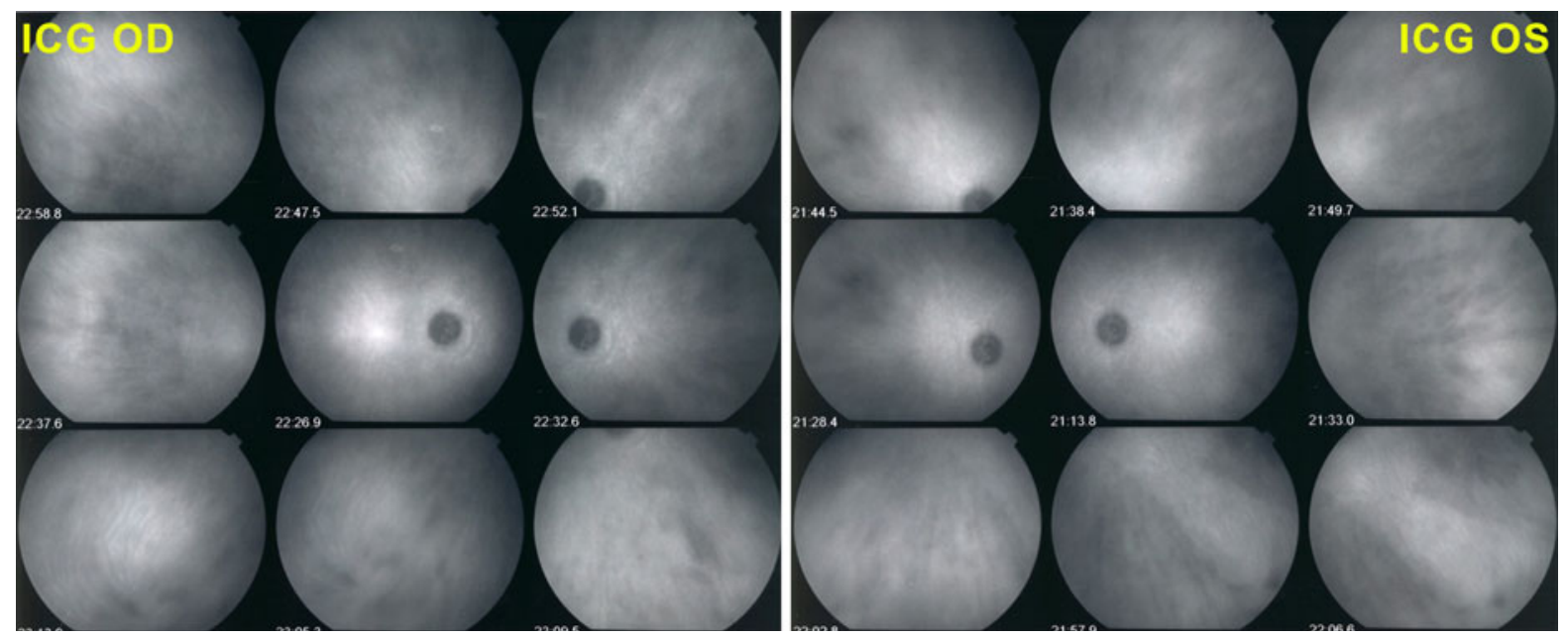

Fig. 3 ICGA showing hypofluorescent dark dots OU and fuzziness of choroidal vessels (OD left figure, OS right figure)
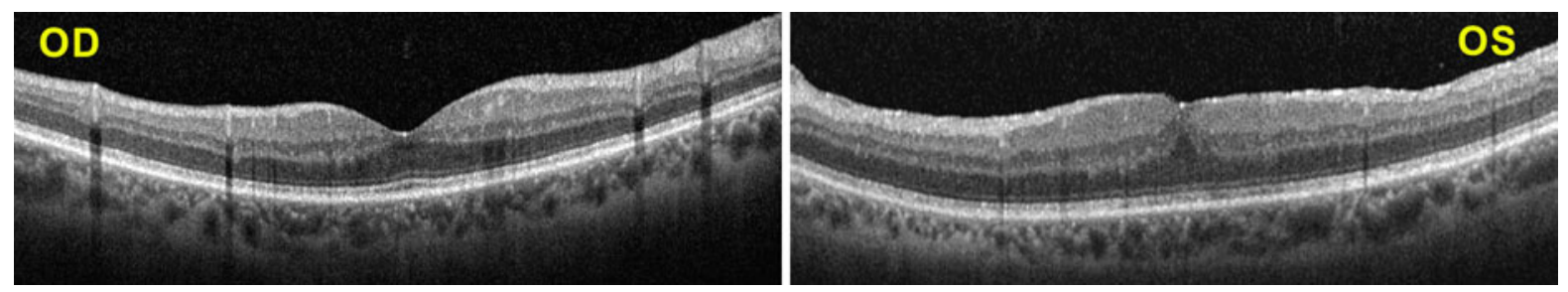

Fig. 4 OCTs of right and left maculas showing resolution of CMO OS after anti-tuberculous therapy; the left macula still showing an increased thickness (right picture)

and BCVA improved in the left eye to 1.0 with a decrease of flare to $40.2 \mathrm{ph} / \mathrm{ms}$.

\section{Discussion}

When intraocular inflammation is not responding to adequate inflammation suppressive therapy (IST), an infectious cause should be suspected. The patient presented here was first treated as a common postsurgical inflammation in his left eye after a combined cataract and ERM operation but was resistant to both one intraocular and repeated sub-Tenon's injections of triamcinolone. Since a complete uveitis work-up showed occult choroiditis on ICGA as well as a positive IGRA test, the diagnosis of presumed ocular tuberculosis was made. A classical triple anti-tuberculous therapy was initiated following flexible bronchoscopy performed because of a persistent upper right lobe infiltrate.
IGRA tests are very helpful, especially in nonendemic areas, to orient the diagnosis of IST-resistant uveitis cases towards possible ocular tuberculosis in case of IGRA positivity with a compatible clinical presentation. In such a situation the patient should be considered to have ocular tuberculosis until proven otherwise and specific treatment is warranted $[3,4,13$, 14]. However, it is not well known that IGRA tests are in fact not only identifying $M$. tuberculosis complex but also at least five NTMs including M. kansasii, M. szulgai, M. marinum, M. gordonae and M. flavescens that can cause ocular infections [6, 7]. This is indicated in Table 1 showing significant cross-reactivity between $M$. tuberculosis complex and environmental strains such as $M$. kansasii, M. szulgai, M. marinum, M. gordonae, M. flavescens, M. gastri, $M$. flavescens and $M$. riyadhense (Table 1).

After having started anti-tuberculous therapy in our patient, a bronchial aspirate culture yielded the NTM M. kansasii. Non-tuberculosis mycobacteria are 
Table 2 Eye infections caused by non-tuberculous mycobacteria
Table shows nontuberculous mycobacterium which cause different ocular diseases, as well as IGRA cross-reactivity characteristics and type of growth

$R G M$ rapidly growing mycobacteria, $S G M$ slowgrowing mycobacteria

\begin{tabular}{|c|c|c|c|}
\hline $\begin{array}{l}\text { Name of } \\
\text { mycobacterium }\end{array}$ & $\begin{array}{l}\text { IGRA cross- } \\
\text { reactivity }\end{array}$ & $\begin{array}{l}\text { Type of growth: } \\
\text { SGM, RGM }\end{array}$ & Type of ocular disease \\
\hline M. abcessus & - & RGM & $\begin{array}{l}\text { Keratitis [37], endophthalmitis } \\
{[39,40]}\end{array}$ \\
\hline M. asiaticum & - & SGM & Keratitis [41] \\
\hline M. avium-intracellulare & - & SGM & Keratitis [41], corneal ulcer [42] \\
\hline M. chelonae & - & RGM & $\begin{array}{l}\text { Keratitis }[16,41] \text {, orbital } \\
\text { granuloma [44], } \\
\text { endophthalmitis }[38,40]\end{array}$ \\
\hline M. flavescens & \pm & SGM & Keratitis [28] \\
\hline M. fortuitum & - & RGM & Keratitis [41], cornea ulcer [43] \\
\hline M. gordonae & + & SGM & Keratitis $[26,27]$ \\
\hline M. kansasii & + & SGM & Chorioretinitis [10] \\
\hline M. marinum & + & SGM & $\begin{array}{l}\text { Keratitis [23], sclerokeratittis [22], } \\
\text { preseptal } \\
\text { cellulitis [24] }\end{array}$ \\
\hline M. nonchromogenicum & - & SGM & Keratitis [41] \\
\hline M. szulgai & + & SGM & Keratitis [16], keratouveitis [25] \\
\hline M. trivial & - & SGM & Keratitis [41] \\
\hline
\end{tabular}

subdivided into three groups of slow-growing strains (SGMs) where M. kansasii, M. marinum, M. szulgai and $M$. gordonae are included and one group of rapidly growing strains [15]. Ocular infections are mostly caused by $M$. abcessus and $M$. chelonae, a rapidly growing mycobacteria (RGM), which is mostly involved in keratitis reports [16-18] and which does not produce a positive IGRA test [19]. Moreover, tuberculosis-like chorioretinitis has also been reported in association with a non-characterised RGM [9]. Grenzebach et al. [11] have reported a case of granulomatous tuberculous-like endophthalmitis caused by an atypical rapidly growing mycobacterium strain. In a case of scleritis, Tanemoto et al. [12] were able to identify an atypical mycobacterium by PCR in eye discharge and gastric juices while culture and microscopy were negative.

Although very rare, all five SGM NTMs cited above that produce a positive IGRA test have been reported to cause intraocular inflammation. Table 2 shows nontuberculous mycobacteria which cause different ocular diseases together with their IGRA crossreactivity characteristics and type of growth. Lai et al. [10] reported a case of systemic dissemination of M. kansasii including tuberculosis-like chorioretinitis and cytomegalovirus retinitis in a patient with acquired immune deficiency syndrome. Other cases of non-ocular infections by $M$. kansasii in immunosuppressed as well as in immunocompetent patients have been described [20,21]. One case of keratitis, one case of sclerokeratitis and one case of preseptal cellulitis due to M. marinum [22-24], one case of keratouveitis and two cases of post-LASIK keratitis due to $M$. szulgai have been reported in the literature $[16,25]$. M. gordonae was also shown to cause keratitis and was isolated by culture [26, 27]. Bullington et al. [28] published a case of M. flavescens keratitis and confirmed that cultures and sensitivity tests are mandatory in determining appropriate treatment.

Fortunately, there are no negative therapeutic consequences in case of $M$. kansasii infections misdiagnosed as $M$. tuberculosis following a positive IGRA test, as this strain is usually sensitive to standard anti-tuberculous therapy [21, 29]; however, the recommended duration of treatment is 18 months [30, 31]. In contrast, if infections due to M. szulgai, M. gordonae, $M$. flavescens or $M$. marinum are misdiagnosed as tuberculosis due to a positive IGRA test, this can have deleterious therapeutic consequences as these SGM NTMs are resistant to standard anti-tuberculous therapy [32,33]. The combination of trimethoprime/sulfametoxazole and doxycycline has been suggested for infections due to M. szulgai and 
M. marinum [34]. M. gordonae was reported to be sensitive to azithromycin, rifampin and quinolones $[35,36]$. In the present case, the clinical response after nine months of therapy has been spectacular with no recurrence so far.

In conclusion, if ocular clinical findings are compatible with a tuberculous uveitis in presence of a positive IGRA test, ocular tuberculosis should be strongly suspected and a therapeutic trial is warranted. As IGRA tests do not react with most of the NTMs, they do react with M. kansasii, M.szulgai, M. gordonae, M. flavescens and M. marinum and an IGRA test cannot exclude an infection by these agents. Although this is a very rare occurrence, it deserves to be known for potential cases resistant to standard anti-tuberculous therapy. In the reported case we strongly suspect that the same organism as the one found in the lung was causing the ocular disease. Fortunately, the consequences would not have been deleterious, unlike for M. szulgai, M. gordonae, M. flavescens or M. marinum, if the organism had not been isolated in the lung as both M. tuberculosis and M. kansasii are sensitive to the same drugs.

\section{References}

1. Abu El-Asrar A, Al-Mezaine HS (2010) Anti-tuberculous therapy combined with systemic corticosteroids improves retinal sensitivity in patients with active presumed tuberculous choroiditis. Int Ophthalmol 30:567-576

2. Bouchenaki N, Herbort CP (2011) Indocyanine green angiography guided management of Vogt-KoyanagiHarada disease. J Ophthalmic Vis Res 6:241-248

3. Papadia M, Herbort CP (2011) Unilateral papillitis, the tip of the iceberg of bilateral ICGA-detected tuberculous choroiditis. Ocul Immunol Inflamm 19:124-126

4. De Luigi G, Mantovani A, Papadia M, Herbort CP (2012) Tuberculous-related choriocapillaris (multifocal-serpiginous choroiditis): follow-up and precise monitoring of therapy by indocyanine green angiography. Int Ophthalmol 17 (Epub Ahead of Print)

5. Lalvani A (2007) Diagnosing tuberculosis infection in the 21st century: new tools to tackle an old enemy. Chest 131:1898-1906

6. Lalvani A, Pareek M (2010) Interferon gamma release assays: principles and practice. Enferm Infecc Microbiol Clin 28:245-252

7. Vordermeier HM, Brown J, Cockle PJ, Franken WPJ, Arend SM, Ottenhoff THM, Jahans K, Hewinson RG (2007) Assessment of cross-reactivity between Mycobacterium bovis and M. kansasii ESAT-6 and CFP-10 at the T-cell epitope level. Clin Vaccine Immunol 14:1203-1209
8. Ingen J, Zwaan R, Dekhuijzen R, Boeree M, Soolingen D (2009) Region of difference 1 in nontuberculous mycobacterium species adds a phylogenetic and taxonomical character. J Bacteriol 191:5865-5867

9. Sinawat S, Yospaiboon Y, Sinawat S (2011) Bilateral endogenous endophthalmitis in disseminated NTM infection: a case report. J Med Assoc Thai 94:632-636

10. Lai LL, Chen SN, Kuo YH, Ho JD, Ho CL (2002) Presumed choroidal atypical tuberculosis superinfected with cytomegalovirus retinitis in an acquired immunodeficiency syndrome patient: a case report. Jpn J Ophthalmol 46: 463-468

11. Grenzebach UH, Busse H, Tötsch M, Dockhorn-Dworniczak B (1996) Endophthalmitis induced by atypical mycobacterial infection. Ger J Ophthalmol 5:202-206

12. Tanemoto K, Ishikawa $\mathrm{H}$, Kigasawa $\mathrm{K}$, Obazawa $\mathrm{H}$, Fusegawa H, Miyachi H, Ando Y (1997) Detection of mycobacterial DNA with polymerase chain reaction in eye discharge and gastric juices in a case of scleritis. Nihon Ganka Gakkai Zasshi 101:97-101

13. Gineys R, Bodaghi B, Carcelain G, Cassoux N, le Boutin TH, Amoura Z, Lehoang P, Trad S (2011) QuantiFERONTB gold cut-off value: implications for the management of tuberculosis-related ocular inflammation. Am J Ophthalmol 152:433-440

14. Bansal R, Gupta A, Gupta V, Dogra MR, Bambery P, Arora SK (2008) Role of anti-tubercular therapy in uveitis with latent/manifest tuberculosis. Am J Ophthalmol 146:772779

15. Jarzembowski JA, Young MB (2008) Nontuberculous mycobacterial infections. Arch Pathol Lab Med 132:13331341

16. Freitas D, Alvarenga L, Sampaio J, Mannis M, Sato E, Sousa L, Vieira L, Yu MC, Martins MC, Hoffling-Lima A, Belfort R Jr (2003) An outbreak of Mycobacterium chelonae infection after LASIK. Ophthalmology 110:276-285

17. Brown-Elliott BA, Mann LB, Hail D, Whitney C, Wallace RJ Jr. (2012) Antimicrobial susceptibility of nontuberculous mycobacteria from eye infections. Cornea [Epub Ahead of Print]

18. Girgis DO, Karp CL, Miller D (2011) Ocular infections due to nontuberculous mycobacteria: update on epidemiology and management. Clin Experiment Ophthalmol [Epub Ahead of Print]

19. Shen GH, Chiou CS, Hu ST, Wu KM, Chen JH (2011) Rapid identification of the Mycobacterium tuberculosis complex by combining the ESAT-6/CFP-10 immunochromatographic assay and smear morphology. J Clin Microbiol 49:902-907 Epub 2010 Dec 15

20. Kaur P, Fishman JA, Misdraji J, Varma MC, Kotton CN (2011) Disseminated Mycobacterium kansasii infection with hepatic abscesses in a renal transplant recipient. Transpl Infect Dis 13:531-535

21. Shitrit D, Baum GL, Priess R, Lavy A, Shitrit AB-G, Raz M, Shlomi D, Daniele B, Kramer MR (2006) Pulmonary Mycobacterium kansasii infection in Israel, 1999-2004: clinical features, drug susceptibility, and outcome. Chest 129:771-776

22. Schonherr U, Naumann GOH, Lang GK, Bialasiewicz AA (1989) Sclerokeratitis caused by Mycobacterium marinum [letter]. Am J Ophthalmol 108:607-608 
23. David DB, Hirst LW, McMillen J, Whitby M (1999) Mycobacterium marinum keratitis: pigmentation a clue to diagnosis. Eye (London) 13:377-379

24. Benton J, Karkanevatos A (2007) Preseptal cellulitis due to Mycobacterium marinum. J Laryngol Otol 121(6):606-608

25. Frueh BE, Dubuis $\mathrm{O}$, Imesch $\mathrm{P}$, Böhnke $\mathrm{M}$, Bodmer $\mathrm{T}$ (2000) Mycobacterium szulgai keratitis. Arch Ophthalmol 118:1123-1124

26. Telahun A, Waring GO, Grossniklaus HE (1992) Mycobacterium gordonae keratitis. Cornea 11:77-82

27. Moore MB, Newton C, Kaufman HE (1986) Chronic keratitis caused by Mycobacterium gordonae. Am J Ophthalmol 102:516-521

28. Bullington RH Jr, Lanier JD, Font RL (1992) Nontuberculous mycobacterial keratitis. Report of two cases and review of the literature. Arch Ophthalmol 110:519-524

29. Rastogi N, Goh KS, Guillou N, Labrousse V (1992) Spectrum of drugs against atypical mycobacteria: how valid is the current practice of drug susceptibility testing and the choice of drugs? Zentralbl Bakteriol 277:474-484

30. Santin M, Dorca J, Alcaide F, Gonzalez L, Casas S, Lopez M, Guerra MR (2009) Long-term relapses after 12-month treatment for Mycobacterium kansasii lung disease. Eur Respir J 33:148-152

31. Falkinham JO (1996) Epidemiology of infection by nontuberculous mycobacteria. Clin Microbiol Rev 9:177-215

32. Wang HX, Yue J, Han M, Yang JH, Gao RL, Jing LJ, Yang SS, Zhao YL (2010) Nontuberculous mycobacteria: susceptibility pattern and prevalence rate in Shanghai from 2005 to 2008. Chin Med J (Engl) 123:184-187

33. Dautzenberg B, Truffot C, Mignon A, Rozenbaum W, Katlama C, Perronne C, Parrot R, Grosset J (1991) Rifabutin in combination with clofazimine, isoniazid and ethambutol in the treatment of AIDS patients with infections due to opportunist mycobacteria. Groupe d'Etude et de Traitement des Infections à Mycobacteries Résistantes. Tubercle 72: $168-175$
34. Katoch VM (2004) Infections due to non-tuberculous mycobacteria (NTM). Indian J Med Res 120:290-304

35. Tomiyama Y, Maesaki S, Yong B, Higashiyama Y, Miyazaki Y, Tomono K, Tashiro T, Kohno S (1999) The combination therapy of clarithromycin and sparfloxacin for pulmonary Mycobacterium gordonae infection. Kekkaku 74:457-461

36. Asija A, Prasad A, Eskridge E (2011) Disseminated Mycobacterium gordonae infection in an immunocompetent host. Am J Ther 18:e75-e77

37. Giaconi J, Pham R, Ta CN (2002) Bilateral Mycobacterium abscessus keratitis after laser in situ keratomileusis. J Cataract Refract Surg 28:887-890

38. El-Asrar AM, Tabbara KF (1995) Chronic endophthalmitis after extracapsular cataract extraction caused by Mycobacterium chelonae subspecies abscessus. Eye 9:798-801

39. Marin-Casanova P, Calandria Amiguetti JL, Garcia-Martos P, Lozano DC, Sanabria BH, Puerto Alonso JL et al (2003) Endophthalmitis caused by Mycobacterium abscessus. Eur J Ophthalmol 13:800-802

40. Benz MS, Murray TG, Dubovy SR, Katz RS, Eifrig CW (2003) Endophthalmitis caused by Mycobacterium chelonae abscessus after intravitreal injection of triamcinolone. Arch Ophthalmol 121:271-273

41. Ford JG, Huang AJ, Pflugfelder SC, Alfonso EC, Forster RK, Miller D (1998) Nontuberculous mycobacterial keratitis in south Florida. Ophthalmology 105:1652-1658

42. Knapp A, Stern GA, Hood CI (1987) Mycobacterium avium-intracellulare corneal ulcer. Cornea 6:175-180

43. Turner L, Stinson I (1965) Mycobacterium fortuitum as a cause of corneal ulcer. Am J Ophthalmol 60:329-331

44. Smith RE, Salz JJ, Moors R, Silverstein D, Lewis W (1980) Mycobacterium chelonei and orbital granuloma after tear duct probing. Am J Ophthalmol 89:139-141 